Actas del Seminario Internacional Destinos Turísticos Inteligentes:

nuevos horizontes en la investigación y gestión del turismo

Universidad de Alicante, 26 y 27 de octubre de 2017

\title{
Calp, hacia la sostenibilidad a través de la inteligencia
}

José Francisco Perles Ribes

jose.perles@ua.es

Ana Ramón Rodríguez

anar@ua.es

Instituto Universitario de Investigaciones Turísticas

Universidad de Alicante

\section{Resumen}

En este artículo se analiza la aplicación del concepto de destino turístico inteligente en Calp, un caso representativo de los destinos turísticos del litoral Mediterráneo español. El análisis efectuado pone de manifiesto que el concepto de destino turístico inteligente puede suponer la primera oportunidad real de hacer operativo el concepto de sostenibilidad turística. También en los destinos de masas. Esta defensa se basa en el hecho que, por primera vez, el uso intensivo de la tecnología que conlleva la implantación de un destino turístico inteligente, va a permitir la medición continua de aspectos vinculados a la sostenibilidad que hasta el momento y en ausencia de dicha tecnología, eran difíciles o simplemente imposibles de medir, y por tanto, gestionar.

Palabras clave: Calp, destino turístico inteligente, sostenibilidad turística, tecnología

\section{Abstract}

This article describes the application of the concept of the intelligent tourist destination using Calp - a representative case of the tourist destinations of the Spanish Mediterranean coastline - as a case study. The analysis performed shows that the concept of intelligent tourist destination could be the first real opportunity to make operational the concept of tourism sustainability, also in mass tourism destinations. The rationale for this argument is based on the fact that, for the first time, the intensive use of the technology that entails the implementation of an intelligent tourist destination, will allow the continuous measurement of aspects related to 
Actas del Seminario Internacional Destinos Turísticos Inteligentes:

nuevos horizontes en la investigación y gestión del turismo

Universidad de Alicante, 26 y 27 de octubre de 2017

sustainability that until now and in the absence of this technology, were difficult or simply impossible to measure, and therefore manage.

Keywords: Calp, smart tourism destination, tourism sustainability, technology.

\section{Introducción}

Calpe -Calp en su denominación oficial- es un destino turístico consolidado de la Costa Blanca que a medio y largo plazo enfrentará problemas de sostenibilidad derivados del agotamiento del principal recurso -el suelo disponible- que impulsa su modelo de crecimiento turístico residencial. La última crisis económica entre 2007 y 2013, junto a la pésima situación de muchos destinos competidores en la ribera Mediterránea, ha facilitado experimentar lo que sería un Calp sin crecimiento inmobiliario, pero turísticamente funcionando a plena capacidad, situación que según Perles, Ramón, Vera e Ivars (2017), se ha asemejado más al estadio estacionario descrito por los economistas clásicos que a un verdadero desarrollo sostenible.

A la vista de este escenario se requiere para Calp un camino hacia la sostenibilidad. Las autoridades turísticas han optado por hacerlo, no a través de una vía directa, sino de una manera indirecta, oblicua (Kay, 2011), a través de la inteligencia, promoviendo la conversión de Calp en un destino turístico inteligente (DTI). En este sentido, Calp cuenta con algunos antecedentes en materia de planificación territorial (Plan General de 1998) y turística (Plan de Diversificación del Producto Turístico de 2015), modernización administrativa (Plan de Modernización Municipal de 2007) y cooperación público-privada en el ámbito turístico (Consorcio Calp Tourism, vigente hasta 2015) que permitirían cimentar un verdadero DTI.

En este artículo se analiza el caso de Calp, y se aboga por una aplicación racional, integral y personalizada del concepto DTI, entendiendo que podría suponer una oportunidad real de hacer operativo el concepto de sostenibilidad turística en este destino. Esta defensa se basa en el hecho de que por primera vez, el uso intensivo de la tecnología que conlleva la implantación de un DTI, va a permitir la medición continua de aspectos vinculados a la sostenibilidad que hasta el momento y en ausencia de dicha tecnología, eran difíciles o simplemente imposibles de medir, y por tanto, gestionar. 
Actas del Seminario Internacional Destinos Turísticos Inteligentes:

nuevos horizontes en la investigación y gestión del turismo

Universidad de Alicante, 26 y 27 de octubre de 2017

El artículo se estructura en los siguientes apartados. Tras examinar la literatura relevante en materia de sostenibilidad e inteligencia turística, en el tercer apartado se describe el método de análisis. En el cuarto apartado, se explican los principales resultados detallando la dinámica turística de Calp y su situación actual. En el quinto apartado se examina las acciones emprendidas por el Ayuntamiento para convertir a Calp en un destino turístico inteligente, así como la percepción que tanto empresarios como turistas tiene de Calp como potencial destino turístico inteligente. Finalmente, en el último apartado se establecen las conclusiones más relevantes, y las limitaciones y futuras líneas de investigación en este campo.

\section{Destinos turísticos inteligentes y sostenibilidad, una revisión de la literatura}

\subsection{El concepto de destino turístico y su sostenibilidad}

Los destinos turísticos son entidades flexibles y dinámicas. En un plano territorial, la delimitación de los destinos - nacional, regional, local, etc. - configura entidades distintas con problemas y necesidades de gestión diferentes. En una dimensión temporal, los destinos son vivos, evolucionan y manifiestan un ciclo de vida a la par que se modifican los gustos y necesidades de los turistas que los visitan y los valores y decisiones de sus residentes y gestores (Butler, 1980). Es por ello que inteligencia aplicada a los destinos turísticos ha de respetar la naturaleza dinámica y flexible de los mismos, lo que aconseja huir de soluciones estandarizadas existentes en el mercado que benefician más a las empresas que los comercializan que al propio destino.

Desde los setenta del siglo XX, el concepto de desarrollo sostenible se asocia al establecimiento de algún tipo de límite al crecimiento. En el Informe "Nuestro Futuro Común» (Brundtland, 1987) se oficializó por primera vez el término, definido como «aquel que satisface las necesidades actuales sin comprometer las capacidades de las generaciones futuras para satisfacer sus propias necesidades». Con el tiempo, el concepto se ha ido enriqueciendo tanto en el plano teórico como en la dimensión operativa, proponiendo líneas estratégicas para alcanzar mayores niveles de sostenibilidad en los planos social, ambiental y económico de los territorios. En el ámbito turístico, los intentos más recientes de dar operatividad al término provienen de la Organización Mundial de Turismo (OMT), quien señala doce propósitos del mismo, a saber: viabilidad económica de los destinos 
Actas del Seminario Internacional Destinos Turísticos Inteligentes: nuevos horizontes en la investigación y gestión del turismo

Universidad de Alicante, 26 y 27 de octubre de 2017

a largo plazo; fomento de la prosperidad local; generación de empleo de calidad; fomento de la equidad social -distribución equitativa de los beneficios turísticos-; proporcionar una experiencia satisfactoria a los visitantes sin discriminaciones de género, raza o discapacidad; control y planificación local de los procesos turísticos; mantenimiento de los niveles de bienestar local -calidad de vida local-; fomento de la riqueza cultural -conservación del patrimonio y la cultura-; preservación de la integridad física -paisajes y recursos-; preservación de la diversidad biológica -conservación de las áreas naturales-; máxima eficiencia en el consumo de recursos y limpieza medioambiental -minimización del impacto de la actividad sobre el medio ambiente-. A tal fin, se propone la estructuración de medidas en base a cinco ejes que son la gobernanza y el diseño de la política turística; el desempeño y competitividad económica; empleo y capital humano; reducción de la pobreza y promoción de la inclusión social y la sostenibilidad natural y cultural del desarrollo turístico (OMT, 2013).

Sin embargo, lo cierto es que la sostenibilidad en turismo es, hoy por hoy, más un desiderátum que una realidad, pues más allá de los muchos modelos y la miríada de indicadores existentes, son muy pocas las experiencias de éxito en la aplicación de una verdadera sostenibilidad en los destinos turísticos. Sobre todo, allí donde es más necesaria, que es en los destinos turísticos de masas más consolidados (Wall, 1992). Y es que como señalan Vera et al. (2001), la aplicación de los principios de la sostenibilidad al turismo participa de la dicotomía existente entre su amplia difusión y las limitaciones de los progresos alcanzados. Así, las definiciones del desarrollo turístico sostenible han venido adoptando la forma de un conjunto, generalmente numeroso, de principios que respetan la complejidad del concepto pero que dificulta su sencilla y correcta comprensión, sobre todo por parte de los profesionales del turismo.

En nuestro caso concreto de estudio, para que Calp se convierta en un destino sostenible será necesario que el turismo sea capaz de relevar en este municipio a la promoción inmobiliaria y a la construcción como motor de riqueza y empleo estable, contribuyendo al bienestar de la sociedad local, fijando los niveles de población residente en el destino, y proponiendo un futuro para las nuevas generaciones de residentes y visitantes que están por llegar (Perles, Ramón, Vera e Ivars, 2017). 
Actas del Seminario Internacional Destinos Turísticos Inteligentes:

nuevos horizontes en la investigación y gestión del turismo

Universidad de Alicante, 26 y 27 de octubre de 2017

\subsection{El destino turístico inteligente}

Según Del Chiappa \& Baggio (2015), el concepto de DTI es un concepto incipiente y dinámico, y sobre el que como en el caso de la sostenibilidad, no existe todavía un consenso general. Existen así diferentes prismas -el plano territorial, la perspectiva de la gestión pública, la visión de los agentes privados, etc. - desde los que los destinos turísticos pueden ser conceptualizados (Ivars, Solsona, \& Giner, 2016)

A pesar del estado primigenio del concepto, el mismo ha sido recibido con mucho interés en varios países, siendo España uno de los más relevantes (Gretzel, Sigala, et al., 2015). El principal apoyo ha venido de instituciones como AENOR y SEGITTUR que define a los destinos turísticos inteligentes como «un espacio turístico innovador, accesible para todos, consolidado sobre una infraestructura tecnológica de vanguardia que garantiza el desarrollo sostenible del territorio, facilita la interacción e integración del visitante con el entorno e incrementa la calidad de su experiencia en el destino y la calidad de vida de los residentes» (SEGITTUR, 2015: 32).

Con estas mimbres, resulta evidente que el concepto entronca claramente con el de smart cities (Buhalis \& Amaranggana, 2015; Ivars et al., 2016), por su énfasis en la aplicación de la tecnología al turismo (Xiang, Tussyadiah, et al., 2015) y el desarrollo de sistemas inteligentes (Gretzel, 2011). En la esencia misma del concepto se encuentra la interconexión entre los diferentes agentes del destino, a través de una plataforma central o central de inteligencia, que recibe los inputs de diversas fuentes interconectadas $y$ transforma los datos en información y servicios a fin de que las instituciones gestionen de la forma más eficiente posible el destino y las empresas ofrezcan servicios de valor añadido que se traduzcan en experiencias más satisfactorias para los turistas (Boes, Buhalis, \& Inversini, 2016; Buhalis \& Amaranggana, 2014).

Con todo, y el mayor o menor énfasis otorgado a la tecnología, quizá lo más relevante del concepto es que el destino turístico inteligente engloba, entre sus muchos aspectos, la sostenibilidad. Sin sostenibilidad un destino no puede ser conceptualizarlo como inteligente. Junto a la sostenibilidad, otros aspectos comprendidos bajo el paraguas del destino turístico inteligente son la propia tecnología -conectividad y sensorización, el sistema de información inteligente e innovación - y la gobernanza del destino (Agencia Valenciana de Turismo, 2015). 
Actas del Seminario Internacional Destinos Turísticos Inteligentes:

nuevos horizontes en la investigación y gestión del turismo

Universidad de Alicante, 26 y 27 de octubre de 2017

El concepto resulta así ambicioso, puesto que, si no ha sido posible alcanzar hasta ahora la ansiada sostenibilidad -que es una parte del concepto-, parece complicado que pueda llevarse a cabo un todo más amplio - la inteligencia - en el que la sostenibilidad es simplemente uno de los elementos. Sin embargo, esta visión puede resultar simplista, en la medida en que no tiene en cuenta las potenciales interacciones que el uso intensivo de la tecnología puede promover en la receta. En este contexto, las oportunidades que abren elementos como la sensorización o el big data, con la monitorización y medición de todo tipo de comportamientos turísticos y subsistemas del destino -gestión de agua, residuos, movilidad urbana, etc.- puede contribuir a determinar los verdaderos costes y beneficios de cada modelo de desarrollo turístico, estableciendo la rentabilidad de los mismos e informando las decisiones sobre cuál de ellos es susceptible de ser favorecido por los policy-makers.

Con relación a nuestro caso de estudio, y a la vista de lo anterior, para conceptualizar a Calp como un DTI esté habrá de ser, en primer lugar, un destino sostenible, para a partir de ahí, mejorar los niveles de satisfacción de la experiencia turística mediante el uso de la tecnología, y sin olvidar aquellos aspectos vinculados a la gobernanza que favorezcan que el turismo sea una actividad participada y aceptada por todos los residentes y agentes implicados, lo que sin duda supondrá un perfeccionamiento respecto de la situación actual del destino turístico.

A continuación, se examina la experiencia de Calp en materia de inteligencia turística, haciendo hincapié en el enfoque o visión amplia del concepto de inteligencia, el carácter integral de las medidas a adoptar y en la orientación hacia la sostenibilidad del destino de las iniciativas emprendidas. Todo ello con el fin de valorar si efectivamente, la inteligencia puede suponer para Calp una verdadera vía hacia la sostenibilidad a medio y largo plazo.

\section{Método}

Para el análisis del estudio de caso se utiliza una metodología combinada basada en el estudio de una serie de indicadores, y en una encuesta efectuada tanto a visitantes como a la oferta turística del municipio por el Ayuntamiento de Calp en 2016. En la vertiente de la oferta, se han efectuado 90 encuestas telefónicas en plataforma CATI a responsables de las empresas del cluster turístico, por medio de un muestro aleatorio estratificado entre el 12 de septiembre y el 4 de octubre de 2016. Suponiendo un universo de 
Actas del Seminario Internacional Destinos Turísticos Inteligentes:

nuevos horizontes en la investigación y gestión del turismo

Universidad de Alicante, 26 y 27 de octubre de 2017

estudio de 709 equipamientos turísticos, para un intervalo de confianza del $95,5 \%$ y un porcentaje de la característica $\mathrm{P}=\mathrm{Q}=50 \%$, se estima un error a priori de las proporciones del $\pm 9,86 \%$. Por lo que respecta a la vertiente de la demanda, se ha considerado una población infinita desconocida, por lo que se han efectuado 800 encuestas presenciales entre el 27 de julio y el 9 de octubre de 2016. Para un intervalo de confianza del mismo nivel de significación y el mismo porcentaje de la característica, se estima un error a priori de las proporciones del $\pm 3,52 \%$.

El cuestionario ha incluido un bloque de preguntas, tanto para empresarios como para turistas, relacionados con la sostenibilidad del destino, o mejor dicho, el papel motriz para la economía local que se percibe a medio plazo del sector turístico.

\section{Resultados: Calp: ¿un destino turístico inteligente?}

Calp es un destino turístico consolidado de la provincia de Alicante representativo de la dinámica experimentada por el conjunto litoral Mediterráneo español que ha sido utilizado como unidad de análisis en diversos ámbitos de la competitividad de destinos y el desarrollo local por Perles (2004, 2009, 2010 y 2014). Como muchos destinos de su entorno, este municipio sufrió un rápido crecimiento y una profunda transformación hasta alcanzar un alto grado de competitividad en el producto de "Sol y Playa» familiar, en el que junto a un concepto vacacional coexiste un fuerte componente residencial cuyos efectos arrastre han propiciado tras de sí el desarrollo de un potente sector inmobiliario, manifestando la terna hostelería-comercio-construcción un peso abrumador como fuente de riqueza y empleo (Perles, 2014).

Como se ha dicho en la introducción, el destino tiene en el agotamiento del suelo disponible su principal límite al crecimiento. La confluencia de la última crisis económica con la carencia de seguridad en algunos países competidores de la ribera Mediterránea ha permitido vislumbrar lo que sería un Calp sin desarrollo inmobiliario ni construcción, pero con un turismo plenamente desplegado. Tras analizar la situación actual del destino en términos de planificación o improvisación de la misma, la visión optimista o pesimista con la que ésta se percibe y las consecuencias sobre las capas más desfavorecidas de la población, Perles, Ramón, Vera e Ivars (2017) concluyen que la situación asemeja más al estadio estacionario que al desarrollo sostenible. Ante esta situación, se hace necesario adoptar, tanto por la iniciativa pública como por los agentes privados implicados, soluciones que garanticen 
Actas del Seminario Internacional Destinos Turísticos Inteligentes:

nuevos horizontes en la investigación y gestión del turismo

Universidad de Alicante, 26 y 27 de octubre de 2017

la viabilidad del destino a medio y largo plazo, siendo una de las posibles soluciones, hoy por hoy, la aplicación de la inteligencia a la gestión del destino turístico.

Aunque parte de una situación alejada, Calp ha iniciado sus primeros pasos para configurarse en un DTI, bajo el liderazgo del Ayuntamiento y con la colaboración de las empresas turísticas del municipio. Tras establecer los indicadores y elaborar el diagnóstico en el marco de un proyecto de investigación de la Universidad de Alicante, el Ayuntamiento ha llevado a cabo un ambicioso estudio sobre la Oferta y la Demanda Turística de Calp, que ha contemplado un bloque de preguntas sobre la sostenibilidad del destino y el concepto de destino turístico inteligente. Sobre estas bases, se ha aprobado de un Plan Director de DTI que se presume personalizado a las necesidades concretas del destino y compartido por todos los agentes implicados.

Lo que es más relevante, se han dotado las partidas presupuestarias que permitan iniciar las acciones contempladas en el dicho Plan, y se ha obtenido financiación del Fondo Europeo de Desarrollo Regional (FEDER) para el mismo a través de la convocatoria del Ministerio de Hacienda para la puesta en marcha de Estrategias de Desarrollo Urbano Sostenible e Integrado (EDUSI), puesto que el mismo se incorporaba en su integridad como una de las línea de actuación de dicha estrategia en el marco del objetivo temático número 2 "garantizar un mejor uso de las tecnologías de la información» de los fondos estructurales. Se pretende a través de estas acciones demostrar que, por primera vez, la sostenibilidad turística de Calp y la de otros muchos destinos consolidados como éste es posible, y que la misma puede alcanzarse a través de la inteligencia.

Pero antes de describir el plan y efectuar valoración alguna sobre la potencialidad de los resultados, se describen con mayor detalle la situación actual del destino y la percepción que tanto empresarios como turistas manifiestan sobre la posibilidad de que Calp se convierta en un destino inteligente, lo que se efectúa a la luz de los resultados que arrojan el análisis de indicadores efectuado en el marco del proyecto de investigación y el estudio de oferta y demanda que se acaban de mencionar.

\subsection{Calp como destino turístico sostenible: la percepción de empresarios y turistas}

Perles, Ramón, Vera \& Ivars (2017) perfilan una visión medianamente pesimista de la situación actual de Calp. El Departamento de Turismo del 
Actas del Seminario Internacional Destinos Turísticos Inteligentes:

nuevos horizontes en la investigación y gestión del turismo

Universidad de Alicante, 26 y 27 de octubre de 2017

Ayuntamiento de Calp ha llevado a cabo en 2016 un estudio sobre el estado de la oferta y demanda turística, que actualiza uno anterior del año 2000, y que mejora el conocimiento sobre la situación actual Calp y el impacto que han tenido innovaciones recientes como la generalización del uso de Internet, la adopción del euro como moneda única europea, la irrupción de las líneas aéreas de bajo coste y la economía colaborativa. Las características de la encuesta se han descrito en la sección método de este artículo.

Una primera conclusión que arroja el estudio es, que en principio, los problemas de sostenibilidad que puedan aquejar al destino no afectan, por el momento, al grado de satisfacción global de la demanda. Así, los turistas de Calp otorgan una valoración global muy favorable $(8,38$ de media sobre 10) del destino turístico (Ayuntamiento de Calp, 2016:59). Este alto grado de satisfacción no es óbice para que los turistas perciban a Calp como un destino masificado, pues el $63,23 \%$ de los encuestados valoran este destino como bastante o muy masificado (Ayuntamiento de Calp, 2016:60).

A pesar de la dificultad potencial de que los turistas ocasionales fueran capaces de valorar esta cuestión, pero valorando en gran medida que el turista acude a Calp suele ser un turista fiel que ha acudido en más de una ocasión al destino, se les ha preguntado además a los turistas si consideraban que la paralización de la construcción en el municipio durante la última crisis económica había impedido el deterioro del atractivo turístico de Calp, obteniendo que un $49,07 \%$ de los turistas consideraban que dicha paralización no había contribuido a impedir el deterioro del atractivo turístico de Calp y sólo un $36,64 \%$ consideraban que en efecto, la paralización de la actividad constructora había tenido efectos positivos sobre el destino, frenado su deterioro turístico.

Por lo que respecta a los empresarios, se les ha planteado si la paralización de la construcción y su sustitución por la actividad turística tiene alguna incidencia sobre la sostenibilidad del destino. Los resultados (ver Tabla 1) apuntan favorablemente en el sentido de que dicha paralización ha mejorado la calidad de vida de los residentes - un 53,56\% consideran que dicha paralización ha mejorado bastante o mucho la calidad de vida de los residentes- $y$ ha impedido el deterioro del atractivo turístico del municipio -un $43,28 \%$, que supera a este mismo porcentaje para el caso de los turistas, están de acuerdo con dicha afirmación. Además, los empresarios se muestran optimistas sobre la posibilidad de que el turismo sustituya a la 
Actas del Seminario Internacional Destinos Turísticos Inteligentes: nuevos horizontes en la investigación y gestión del turismo

Universidad de Alicante, 26 y 27 de octubre de 2017

construcción como motor de desarrollo en el municipio, pues un 57,91\% de los empresarios están de acuerdo con esta afirmación.

Tabla 1: Percepción de los empresarios sobre la paralización de la construcción y su sustitución por actividades turísticas

\begin{tabular}{|l|c|c|c|c|c|}
\hline $\begin{array}{l}\text { La paralización de la construcción y su } \\
\text { sustitución por la actividad turística } \\
\text { ha... }\end{array}$ & Nada & Poco & Bastante & Mucho & Ns/c \\
\hline $\begin{array}{l}\text { Mejorado la calidad de vida de los } \\
\text { residentes }\end{array}$ & 19,81 & 21,10 & 41,21 & 12,35 & 5,53 \\
\hline $\begin{array}{l}\text { Impedido el deterioro del atractivo } \\
\text { turístico de Calp }\end{array}$ & 25,64 & 24,51 & 34,39 & 8,89 & 6,57 \\
\hline $\begin{array}{l}\text { Demostrado que el turismo puede } \\
\text { sustituir a la construcción como motor } \\
\text { económico }\end{array}$ & 12,06 & 20,06 & 37,90 & 20,01 & 9,98 \\
\hline $\begin{array}{l}\text { Mejorado los salarios de los } \\
\text { trabajadores }\end{array}$ & 44,27 & 23,32 & 17,79 & 1,09 & 13,54 \\
\hline $\begin{array}{l}\text { Mejorado los niveles de empleo y ha } \\
\text { reducido el paro }\end{array}$ & 32,02 & 23,27 & 27,92 & 5,63 & 11,17 \\
\hline $\begin{array}{l}\text { Mejorado las condiciones laborales } \\
\text { (tipos de contratos, horarios, } \\
\text { seguridad...) }\end{array}$ & 40,86 & 27,77 & 16,75 & 2,22 & 12,40 \\
\hline $\begin{array}{l}\text { Sido un proceso planificado por las } \\
\text { instituciones }\end{array}$ & 35,67 & 12,20 & 16,85 & 4,35 & 30,93 \\
\hline
\end{tabular}

Fuente: Encuesta a la oferta turística de Calp, 2016.

Sin embargo, los empresarios se muestran más escépticos sobre la posibilidad de que dicha paralización haya mejorado o pueda mejorar las condiciones de los trabajadores de la localidad. Del mismo modo, y como han subrayado Perles, Ramón, Vera \& Ivars (2017), la mayoría de empresarios considera que dicha paralización no ha sido un proceso planificado por las autoridades, lo que les lleva al convencimiento de que la situación actual de la localidad no se aproxima a un verdadero desarrollo sostenible.

\subsection{Calp como DTI: la lectura de los indicadores}

En el marco de un proyecto de investigación de la Universidad de Alicante, en el que Calp participa como destino piloto en el producto sol y playa, se 
Actas del Seminario Internacional Destinos Turísticos Inteligentes:

nuevos horizontes en la investigación y gestión del turismo

Universidad de Alicante, 26 y 27 de octubre de 2017

ha efectuado una valoración de la situación actual del destino en el ámbito de la inteligencia, mediante el análisis de una serie de indicadores obtenidos mediante fuentes secundarias y debatidos con los técnicos municipales pertenecientes a las áreas de urbanismo, medioambiente, informática-modernización, turismo, cultura y régimen interior.

Los indicadores propuestos por el equipo investigador cubren todos los ámbitos de actuación de un destino turístico inteligente, a saber: gobernanza, sostenibilidad territorial y urbana, sostenibilidad turística, accesibilidad, calidad de vida residencial y cohesión social, conectividad y uso de sensores, información turística, marketing online y actividad turística. Los resultados que se detallan a continuación muestran lógicamente, que el destino aún se encuentra en una fase incipiente de la aplicación del concepto.

En el ámbito de la gobernanza, se valora positivamente la existencia de algunos instrumentos de planificación, como el Plan de Diversificación del Producto Turístico, pero aunque el mismo fue debatido y aprobado por el Pleno del Ayuntamiento tras un periodo de exposición pública, se critica del mismo que no ha contemplado aspectos de madurez tecnológica, así como su falta de participación e interacción ciudadana y su falta de transparencia al no estar incorporado en la web del departamento de turismo. Además, se critica que aunque el plan turístico se coordina con algunas iniciativas como la Agenda XXI Local y la formulación de una reciente Estrategia de Desarrollo Urbano Sostenible e Integral (EDUSI), no muestra conexión con el Plan General de Ordenación Urbana del destino, el instrumento de planificación por excelencia del destino. En definitiva, en términos de planificación, parece necesario que todos estos esfuerzos que habrán de culminar con la aprobación de un Plan Director del Destino Turístico Inteligente, deberán de hacerse de forma consensuada por todos para que sirva de guía para las acciones a emprender en este terreno.

En segundo término, con relación a la cooperación público-privada, la reciente desaparición del Consorcio Calp Tourism a raíz de la normativa sobre racionalidad presupuestaria y de lucha contra la crisis promulgada por el Gobierno central, se ha valorado también como una carencia relevante. Se ha sugerido así la creación de una nueva plataforma que articule la participación público-privada y que dé continuidad a los esfuerzos iniciados en el seno del Consorcio (Perles y Ramón, 2017).

En tercer lugar, hay que destacar que es en el marco de la sostenibilidad urbana, donde se observan las principales carencias para hacer de Calp un 
Actas del Seminario Internacional Destinos Turísticos Inteligentes:

nuevos horizontes en la investigación y gestión del turismo

Universidad de Alicante, 26 y 27 de octubre de 2017

DTI. Y es que Calp, con un $44,43 \%$ de su suelo calificado como urbano o urbanizable, es uno de los municipios que ha efectuado un uso más intensivo de este recurso. A pesar de ello, y gracias a los enormes atractivos con que cuenta el municipio, el medio ambiente es uno de los atributos del destino que ha alcanzado valoraciones más elevadas por parte de los turistas. De acuerdo con el estudio de oferta y demanda turística, las playas han alcanzado un 8,47 sobre 10 de valoración, los recursos naturales un 7,97 y el ambiente un 8,22 sobre 10 (Ayuntamiento de Calp, 2016:57). Otros aspectos relativamente positivos en esta materia son, según los indicadores existentes, la peatonalización del centro histórico y la puesta en marcha de carriles bici en la zona más llana del municipio para fomentar el uso de este vehículo.

Dentro de la misma órbita, el proyecto de Agenda Local XXI llevado a cabo por el Ayuntamiento se ha valorado en un estadio intermedio, sin que exista una publicación exacta de los proyectos llevados a cabo, mientras que los indicadores del mismo están definidos y contemplados en un documento con carácter estático. También se ha valorado desfavorablemente la situación de la movilidad urbana, con un elevado índice de motorización -un vehículo por cada dos personas-, sin que el transporte público pueda resolver las necesidades de la urbanización dispersa.

En materia energética, aunque el municipio participa en el Plan de Ahorro Energético de la provincia de Alicante y se han efectuado algunas acciones en materia de ahorro -como la sustitución de iluminación convencional por tecnología led-, las energías renovables ocupan un papel testimonial. Y ello a pesar de las condiciones idóneas que Calp, como el resto del litoral Mediterráneo, presenta para su proliferación. Y la situación respecto al abastecimiento de agua, aunque ha mejorado mucho respecto de la existente en los años ochenta del siglo XX, resulta un tanto preocupante en la medida en que los recursos hídricos provienen de municipios interiores - a 30 kilómetros de distancia - lo que en ocasiones puntuales genera conflictos por el uso y disposición de este recurso fundamental. Por lo demás, se carece de indicadores relativos a otros aspectos ambientales como la contaminación del aire y la acústica.

Cambiando de plano, en cuarto lugar, en la esfera de la sostenibilidad turística, la sostenibilidad de los recursos turísticos principales -especialmente las playas- se ha valorado muy favorablemente, con una calidad excelente en cuatro de las playas del municipio y una buena según el Real Decreto 1341/2007. Existen también algunas acciones pioneras en materia 
Actas del Seminario Internacional Destinos Turísticos Inteligentes:

nuevos horizontes en la investigación y gestión del turismo

Universidad de Alicante, 26 y 27 de octubre de 2017

de desarrollo de productos y acciones de marketing con enfoque sostenible, como son las acciones dedicadas a la promoción del buceo y del cicloturismo.

En un quinto aspecto analizado, la accesibilidad, se ha valorado en un nivel bajo el cumplimiento, dado que únicamente existe accesibilidad a las playas Arenal-Bol y La Fossa, pero no existen otros recursos turísticos accesibles. Existen deficiencias en cuanto a los niveles de accesibilidad de las webs turística y municipal, así como en las oficinas de turismo y tampoco existe material promocional totalmente satisfactorio desde el punto de vista de la accesibilidad.

En sexto lugar, en cuanto a los indicadores de calidad de vida y cohesión social, lo más relevante es que la renta disponible media del municipio $16.608,00 €$ es ligeramente inferior a la media provincial $(17.090,00 €)$, mientras que los volúmenes de desempleo local se han estabilizado tras haber experimentado un fuerte aumento durante la crisis económica, alcanzando en enero de 2016 la cifra de 1.867 desempleados, y que supone un 9,52\% de la población total del municipio. Según la Seguridad Social, el número de trabajadores asciende a la misma fecha a 5.634 afiliados, que supone el 28,75\% de la población local (19.591 habitantes).

En el séptimo punto, la conectividad, se ha apreciado un nivel medio de conectividad de las empresas turísticas del destino, disponiendo de fibra óptica en el núcleo urbano y optando por una solución $4 \mathrm{G}$ o WIMAX en las urbanizaciones del diseminado. Con relación a la Wi-fi pública gratuita, Calp ha sido uno de los destinos pioneros en esta materia, pero diversos problemas de la empresa adjudicataria han dado al traste con un servicio que era bien valorado por los turistas. Por el contrario, en materia de sensorización el municipio aún no ha adoptado ninguna iniciativa.

En el octavo punto, por lo que respecta a las acciones emprendidas en materia de innovación turística, éstas se han centrado en la mejora de los establecimientos existentes y la construcción de nuevos equipamientos hoteleros más grandes y modernos, así como en la diversificación del producto (puesta en marcha de campers, captación de cicloturistas, etc.). Aparte de estas, no hay acciones reseñables en materia de I+D+i. Y en cuestión de sistemas de información o inteligencia turística, aparte del estudio de oferta y demanda mencionado y la puesta en marcha de un sistema de monitorización propio de la ocupación turística, se aprecia que el destino utiliza los instrumentos facilitados por otras entidades como la Agencia Valenciana de Turismo o la patronal hotelera HOSBEC. Sin embargo, el destino carece una 
Actas del Seminario Internacional Destinos Turísticos Inteligentes:

nuevos horizontes en la investigación y gestión del turismo

Universidad de Alicante, 26 y 27 de octubre de 2017

plataforma de destino turístico inteligente que agrupe toda la información generada por el destino ni existe un cuadro de mando para la visualización de datos estadísticos.

Por último, en materia de información turística y marketing online, la situación es también mejorable, aunque existe una web turística propia, y se despliega una elevada actividad en redes sociales, el destino carece una aplicación propia para dispositivos móviles y efectúa un bajo uso de la tecnología de códigos QR. Del mismo modo, tampoco se usan pantallas táctiles o kioscos de información virtuales que presten servicio cuando las oficinas de información se encuentran cerradas. Con eso y con todo, la calidad de la experiencia turística percibida por los visitantes es, como se ha dicho, muy elevada, e incluso un $69,29 \%$ de los turistas consideran que Calp es un municipio moderno (Ayuntamiento de Calp, 2016:61).

\subsection{Calp como destino turístico inteligente: la percepción de los empresarios}

El estudio de oferta y demanda elaborado por el Ayuntamiento también ha analizado la percepción que tanto unos u otros tienen sobre la potencialidad de Calp para convertirse en un DTI.

En primer lugar, el estudio ha puesto de manifiesto que los empresarios turísticos locales tienen un bajo grado de conocimiento del concepto de DTI. Así, un $66 \%$ de los empresarios confiesan que no saben qué es un DTI y un $18,63 \%$ de los encuestados no contestan a la pregunta, por lo que se entiende que tampoco lo conocen con certeza. Sólo el 14,43\% de los empresarios es capaz de dar una contestación parcial, que incluye al menos alguna de las características definitorias de turismo inteligente (Ayuntamiento de Calp, 2016:72). Sobre aquellas características de un DTI identificadas por la literatura, los empresarios atribuyen a Calp su presencia en webs y redes sociales y su accesibilidad y sostenibilidad. Por el contrario, menos del $30 \%$ entienden que Calp ofrece experiencias bastante o muy diferenciadas de otros destinos tradicionales; y sólo un 33\% considera favorablemente la cooperación entre Ayuntamiento y empresas (ver Tabla 2).

La acción más demandada por los empresarios para consolidar a Calp como DTI (ver Tabla 3) es mejorar la reputación de Calp en internet y redes sociales, siendo más de un $90 \%$ de empresarios los que ven esta acción como bastante o muy prioritaria. Le sigue muy de cerca ofrecer wifi gratuitamente en espacios públicos y crear una aplicación turística de Calp para móviles, 
Actas del Seminario Internacional Destinos Turísticos Inteligentes: nuevos horizontes en la investigación y gestión del turismo

Universidad de Alicante, 26 y 27 de octubre de 2017

Tabla 2: Calp como destino turístico inteligente, la percepción de los empresarios

\begin{tabular}{|c|c|c|c|c|c|}
\hline Calp es un destino turístico... & Nada & Poco & Bastante & Mucho & $N s / c$ \\
\hline Innovador & 26,38 & 29,15 & 35,62 & 8,84 & 0,00 \\
\hline Accesible a minusválidos & 2,22 & 29,05 & 59,73 & 8,99 & 0,00 \\
\hline Sostenible & 7,76 & 26,53 & 57,76 & 5,68 & 2,27 \\
\hline Que usa las últimas tecnologías & 6,62 & 36,66 & 41,21 & 4,45 & 11,07 \\
\hline Con presencia en webs y redes sociales & 0,00 & 23,27 & 54,55 & 15,56 & 6,62 \\
\hline Que ofrece experiencias de alta calidad & 9,83 & 32,16 & 47,88 & 7,86 & 2,27 \\
\hline $\begin{array}{l}\text { Ofrece actividades distintas a otros } \\
\text { destinos }\end{array}$ & 22,23 & 42,09 & 25,69 & 3,36 & 6,62 \\
\hline Con una alta colaboración empresarial & 7,76 & 39,72 & 41,40 & 7,76 & 3,36 \\
\hline $\begin{array}{l}\text { En el que cooperan Ayuntamiento y } \\
\text { empresas }\end{array}$ & 21,89 & 38,88 & 31,37 & 4,50 & 3,36 \\
\hline
\end{tabular}

Fuente: Encuesta a la oferta turistica de Calp, 2016.

Tabla 3: Acciones señaladas por los empresarios para convertir a Calp en un destino turístico inteligente

\begin{tabular}{|l|c|c|c|c|c|}
\hline $\begin{array}{l}\text { ¿Considera prioritarias las siguientes } \\
\text { acciones? }\end{array}$ & Nada & Poco & Bastante & Mucho & Ns/c \\
\hline $\begin{array}{l}\text { Poner wifi gratis en los espacios públicos } \\
\text { de Calp }\end{array}$ & 4,35 & 7,71 & 47,78 & 39,08 & 1,09 \\
\hline $\begin{array}{l}\text { Crear una aplicación turística de Calp } \\
\text { para móviles }\end{array}$ & 3,26 & 8,79 & 55,48 & 30,29 & 2,17 \\
\hline $\begin{array}{l}\text { Crear un motor de reservas de Calp, } \\
\text { donde comercializar su oferta }\end{array}$ & 8,89 & 12,35 & 49,65 & 26,88 & 2,22 \\
\hline $\begin{array}{l}\text { Mejorar la información estadística sobre } \\
\text { la demanda turística de Calp }\end{array}$ & 3,36 & 9,83 & 52,32 & 29,99 & 4,50 \\
\hline $\begin{array}{l}\text { Crear una tarjeta turistica que integre la } \\
\text { oferta del municipio }\end{array}$ & 4,40 & 14,53 & 52,27 & 25,49 & 3,31 \\
\hline $\begin{array}{l}\text { Mejorar la reputación de Calp en } \\
\text { internet y redes sociales }\end{array}$ & 1,09 & 5,48 & 47,97 & 44,32 & 1,14 \\
\hline $\begin{array}{l}\text { Administración electrónica para facilitar } \\
\text { los trámites a las empresas turísticas }\end{array}$ & 4,35 & 8,84 & 53,46 & 28,95 & 4,40 \\
\hline $\begin{array}{l}\text { Crear códigos QR en los recursos } \\
\text { turísticos para informar mejor }\end{array}$ & 7,76 & 16,65 & 47,92 & 17,74 & 9,93 \\
\hline $\begin{array}{l}\text { Técnicas de realidad virtual para hacer } \\
\text { los recursos turísticos más atractivos }\end{array}$ & 4,40 & 21,20 & 53,31 & 17,84 & 3,26 \\
\hline
\end{tabular}

Fuente: Encuesta a la oferta turística de Calp, 2016. 
Actas del Seminario Internacional Destinos Turísticos Inteligentes:

nuevos horizontes en la investigación y gestión del turismo

Universidad de Alicante, 26 y 27 de octubre de 2017

con más del $85 \%$ de los responsables del negocio bastante o muy a favor de esta propuesta. Por el contrario, la implementación de códigos QR en los recursos turísticos y las técnicas de realidad virtual para hacer los recursos turísticos más atractivos son las acciones menos señaladas.

Luego los empresarios turísticos, de acuerdo con su carácter pragmático, valoran como positiva la aplicación de la tecnología orientada al turista relativamente simple y de amplia difusión actual, como la existencia de una red wifi pública gratuita, las aplicaciones para dispositivos móviles del destino y su posicionamiento en redes sociales, lo que aconsejaría, de acuerdo con este punto de vista, huir de soluciones complejas o tecnologías experimentales de dudosa rentabilidad económica y escaso atractivo para los visitantes.

\subsection{Calp como destino turístico inteligente: la percepción de los turistas}

Ya se ha dicho anteriormente, que a pesar de las carencias y el estado incipiente del destino en materia de inteligencia, un amplio segmento de la demanda ha considerado que Calp es un destino turístico moderno. De forma más concreta el estudio se planteado analizar, en primer lugar, el grado de uso de los distintos dispositivos tecnológicos que efectúan los turistas durante sus vacaciones en Calp. El estudio del Ayuntamiento (ver Tabla 4) deja claro que sólo un $4,71 \%$ de los turistas que acuden a Calp viaja sin dispositivos tecnológicos. Por el contrario, un $94,46 \%$ de los turistas viajan con su smartphone. Otros dispositivos, por su parte, son mucho menos utilizados por los turistas (Ayuntamiento de Calp, 2016:77).

En cuanto al uso efectuado de la tecnología (ver Tabla 5), además de las Ilamadas telefónicas propias del smartphone, un $74 \%$ utiliza los dispositivos para hacer fotos o vídeos, un $66 \%$ para escribir mensajes de texto, un $45,87 \%$ para compartir la experiencia turística en redes sociales, un $44,81 \%$ para consultar mapas o como GPS y un 33\% para buscar restaurantes o alojamientos. Por el contrario, el pago a través de smartphone es minoritario.

El estudio analiza las diferencias de uso en función de la tipología de alojamiento en el que se albergan los visitantes, encontrando que los turistas hospedados en camping están más predispuestos a escribir mensajes de texto y consultar mapas o GPS, los emplazados en viviendas de uso turístico tienden a compartir las experiencias del viaje en las redes, mientras que los albergados en hoteles presentan porcentajes por debajo del resto en todos los usos, salvo en el pago mediante Smartphone. 
Actas del Seminario Internacional Destinos Turísticos Inteligentes: nuevos horizontes en la investigación y gestión del turismo

Universidad de Alicante, 26 y 27 de octubre de 2017

Tabla 4: Dispositivos tecnológicos usados por los turistas de Calp

\begin{tabular}{|l|c|c|c|c|}
\hline $\begin{array}{l}\text { Mientras está de viaje ¿utiliza } \\
\text { algún dispositivo tecnológico? }\end{array}$ & Smartphone & Tabletas & Portátil & Ninguno \\
\hline Vivienda propia & 87,22 & 18,75 & 13,99 & 12,78 \\
\hline Vivienda cedida & 96,21 & 23,96 & 13,14 & 1,73 \\
\hline Vivienda de intercambio & 100,00 & 0,00 & 15,77 & 0,00 \\
\hline Vivienda alquilada & 97,77 & 17,16 & 12,34 & 2,23 \\
\hline Total vivienda & $\mathbf{9 4 , 5 1}$ & $\mathbf{1 8 , 8 7}$ & $\mathbf{1 3 , 0 2}$ & $\mathbf{5 , 0 4}$ \\
\hline Hotel de 4 o más estrellas & 93,32 & 26,20 & 14,89 & 3,85 \\
\hline Hotel de 3 o menos estrellas & 95,14 & 17,24 & 5,80 & 4,10 \\
\hline Hostal o Pensión & 100,00 & 0,00 & 0,00 & 0,00 \\
\hline Total hoteleros & $\mathbf{9 4 , 3 7}$ & $\mathbf{2 1 , 5 1}$ & $\mathbf{1 0 , 9 7}$ & $\mathbf{3 , 6 5}$ \\
\hline Camping & $\mathbf{9 3 , 5 8}$ & $\mathbf{3 7 , 6 8}$ & $\mathbf{2 9 , 3 2}$ & $\mathbf{3 , 2 7}$ \\
\hline Total & $\mathbf{9 4 , 4 6}$ & $\mathbf{1 9 , 8 7}$ & $\mathbf{1 2 , 9 8}$ & $\mathbf{4 , 7 1}$ \\
\hline
\end{tabular}

Multirrespuesta. \% de respondientes en filas.

Fuente: Encuesta a la demanda turística de Calp, 2016.

Tabla 5: Usos concretos de los dispositivos tecnológicos por los turistas de Calp

\begin{tabular}{|l|c|c|c|c|}
\hline $\begin{array}{l}\text { ¿Para qué utiliza los dispositivos } \\
\text { tecnológicos en el viaje? }\end{array}$ & Vivienda & Hotelero & Camping & Total \\
\hline Realizar y recibir llamadas & 98,45 & 90,55 & 97,76 & $\mathbf{9 6 , 7 5}$ \\
\hline Hacer fotos o vídeos & 75,17 & 69,35 & 76,37 & $\mathbf{7 3 , 9 6}$ \\
\hline Escribir mensajes de texto & 65,85 & 58,24 & 71,30 & $\mathbf{6 4 , 3 6}$ \\
\hline Compartir la experiencia en redes & 49,96 & 32,71 & 32,57 & $\mathbf{4 5 , 8 7}$ \\
\hline Consultar mapas o GPS & 46,55 & 37,59 & 53,25 & $\mathbf{4 4 , 8 1}$ \\
\hline Buscar restaurantes, alojamientos... & 33,26 & 26,30 & 35,72 & $\mathbf{3 1 , 8 4}$ \\
\hline Buscar sitios que visitar, cosas que ver... & 31,75 & 23,44 & 25,68 & $\mathbf{2 9 , 8 3}$ \\
\hline Reservar actividades & 17,77 & 6,19 & 13,95 & $\mathbf{1 5 , 2 1}$ \\
\hline Pagar vía Smartphone & 4,82 & 4,84 & 5,61 & $\mathbf{4 , 8 4}$ \\
\hline Otros no relacionados con el turismo & 3,15 & 3,35 & 0,48 & $\mathbf{3 , 1 3}$ \\
\hline
\end{tabular}

Multirrespuesta. \% de respondientes en columnas. Respuestas espontáneas.

Base: Encuestados que usan algún dispositivo tecnológico en el destino.

Fuente: Encuesta a la demanda turística de Calp, 2016. 
Actas del Seminario Internacional Destinos Turísticos Inteligentes:

nuevos horizontes en la investigación y gestión del turismo

Universidad de Alicante, 26 y 27 de octubre de 2017

Por nacionalidad, españoles y extranjeros efectúan usos similares, mientras que por género, los hombres, en mayor medida que las mujeres, consultan mapas o GPS, y sitios para visitar o cosas que hacer. En cuanto a edad, quienes comparten su experiencia en redes sociales suelen ser turistas más jóvenes, con un nivel socioeconómico algo inferior a la media, perfil que se asemeja al de los milenials (Ayuntamiento de Calp, 2016:79).

Respecto al grado de uso de las tecnologías ya implantadas en el destino (ver Figura 1), un $72,4 \%$ de los turistas han utilizado el acceso a internet vía wifi ofrecido por algunas empresas de Calp (normalmente los hoteles de mayor categoría), un $33 \%$ utilizó el wifi público gratuito, y un porcentaje similar visitó la web oficial municipal (sobre todo los alojados en camping, que también suelen consultar las cuentas de Calp en las redes sociales). Menor repercusión ha tenido, por el contrario, las video-guías, los códigos QR, las audio-guías y las apps oficiales de Calp, como corresponde a su escaso desarrollo en el municipio (Ayuntamiento de Calp, 2016:80).

En cuanto a la contribución de la tecnología a la mejora de la experiencia turística (ver Figura 1), se observa que los turistas consideran que, a pesar de su escasa utilización, el pago a través del móvil, las vídeo-guías, el teléfono de atención al cliente y las apps oficiales son los elementos que alcanzan mayor potencialidad, puesto que los turistas les otorgan valoraciones superiores a 8 sobre 10 . El aspecto que menos entusiasmo ha despertado entre sus usuarios es el wifi público que, a pesar de sus deficiencias, ha obtenido un 5,74 .

Como ha establecido el estudio, los turistas alojados en equipamientos hoteleros valoran el del wifi público más positivamente que los alojados en viviendas turísticas. Por el contrario, en el caso de las apps oficiales y las audio-guías son los alojados en las viviendas quienes mejor valoran estos elementos. Por nacionalidades, los extranjeros valoran más el wifi público y privado que los nacionales. Las mujeres valoran en mayor grado los códigos QR y el wifi público gratuito que los hombres y a mayor nivel socioeconómico peor valoración del wifi gratuito y mejor de las audio-guías. Por último, con relación a la edad, a menor edad mejor evaluación de las cuentas de Calp en las redes sociales, y viceversa (Ayuntamiento de Calp, 2016:80-81).

Finalmente, dada la importancia que tiene el boca-oído virtual en el ámbito de la promoción turística, se ha cuestionado de forma directa a los turistas su predisposición a compartir sus experiencias en dichos soportes, habiendo obtenido una respuesta afirmativa para el $58 \%$ de los encuestados. 
Actas del Seminario Internacional Destinos Turísticos Inteligentes:

nuevos horizontes en la investigación y gestión del turismo

Universidad de Alicante, 26 y 27 de octubre de 2017

Figura 1: Contribución de la tecnología a la mejora de la experiencia turística.

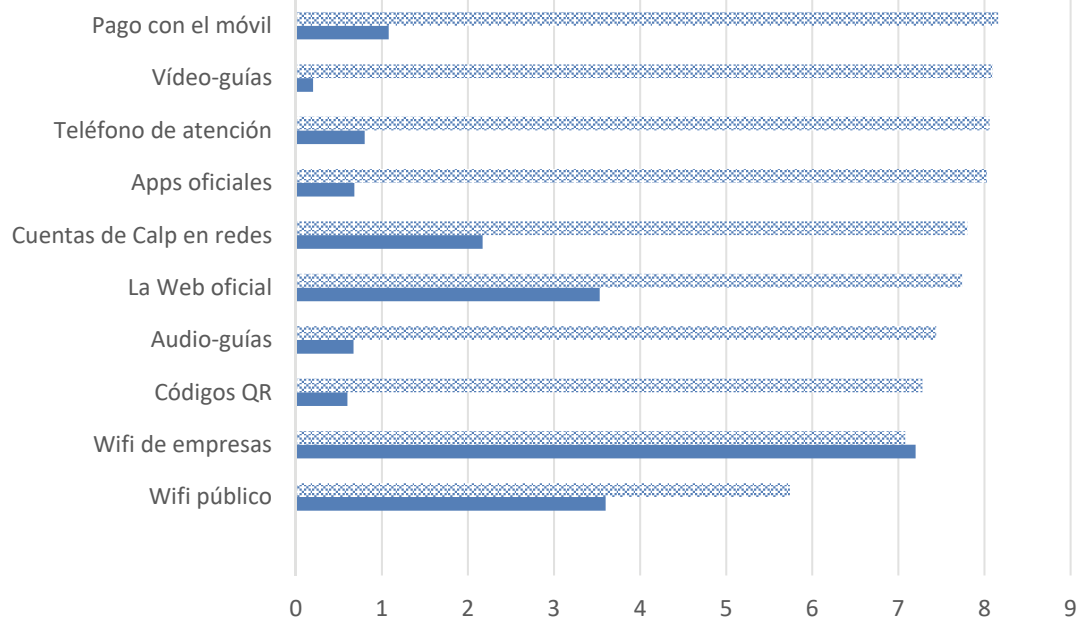

Fuente: Encuesta a la demanda turística de Calp, 2016.

Nota: trama valoración, sólido uso.

De conformidad con el perfil y el comportamiento de quienes suelen usar este tipo de tecnología, quienes reservaron el alojamiento por medio de buscadores son más propensos a transmitir a otros su vivencia en Calp. En concreto, han afirmado subir a las redes su experiencia las personas de menor edad (media de 39,58 años), renta más modesta y que pernoctan menos días en Calp ( 2 semanas). En particular, se muestran muy proclives a esta práctica los que viajan solos $(71,56 \%)$ o con amigos $(85,65 \%)$. Por contra, exponen en menor medida o no exponen en ningún modo su experiencia en redes sociales las personas de edad más avanzada (51 de media), con rentas algo más elevadas y que permanecen más días (sobre 20 en media) en el destino (Ayuntamiento de Calp, 2016:82).

En conclusión, a pesar del escaso desarrollo tecnológico del municipio, los turistas han valorado favorablemente aquellas iniciativas que están en funcionamiento, tales como la web municipal y las cuentas en redes sociales oficiales del destino. Estas tecnologías, como se ha dicho, son de entre las nuevas tecnologías las más clásicas y las que cuentan con mayor difusión en todos los destinos. Los turistas también han valorado positivamente la 
Actas del Seminario Internacional Destinos Turísticos Inteligentes:

nuevos horizontes en la investigación y gestión del turismo

Universidad de Alicante, 26 y 27 de octubre de 2017

posibilidad de pagar a través del móvil, sin embargo es ésta una opción todavía minoritaria entre los turistas. Por el contrario, otras tecnologías tal vez más sofisticadas como la existencia de audioguías o los códigos QR ni son utilizadas por los turistas -lo que sin duda puede deberse al bajo nivel de implantación que actualmente tienen en el municipio - ni son especialmente demandadas por los turistas como elementos básicos capaces de contribuir a la mejora de su experiencia turística.

\section{Discursión: el plan director de DTI de Calp}

Actualmente y con base a todos los elementos anteriores, el Ayuntamiento de Calp ha redactado y aprobado inicialmente un Plan Director de Destino Turístico Inteligente. ${ }^{1}$ El Plan propone dos grandes áreas de actuación, una línea de carácter estratégico que comprende actuaciones en las áreas de la innovación, la accesibilidad y la sostenibilidad y gobernanza de los destinos inteligente; y una segunda línea de acción tecnológica que comprende los ámbitos de la información y marketing y la conectividad, sensorización y captación de datos.

La tabla 6 refleja las acciones comprendida por cada área de actuación hasta un total de 24 que, al configurar en su totalidad el bloque tecnológico de la EDUSI de Calp que ha resultado beneficiaria de la financiación europea, cuya implementación se producirá entre 2017 y 2022. A fecha actual, y en el marco de la EDUSI ya ha sido formalizada la ficha de acción y el esquema de gobernanza del plan, de conformidad con las instrucciones remitidas desde el Organismo Intermedio de Gestión de los fondos FEDER.

En cualquier caso, lo más relevante no son las acciones descritas y la mera tecnología que pueda aplicarse en el uso de las mismas, sino el verdadero espíritu de las mismas y que en la línea argumental de este trabajo, se consiga mediante la aplicación de la tecnología un alcance más allá de la mera provisión de información al turista o la implementación de una mera herramienta de marketing, y permita alcanzar una verdadera sostenibilidad del destino por medio de la aplicación de una verdadera inteligencia y la mejor gestión que la misma puede propiciar. Para ello, la tecnología habrá de alcanzar muchos más aspectos como, por ejemplo, en el caso de

1. El Plan fue aprobado inicialmente por el Ayuntamiento Pleno en fecha 9 de mayo de 2017, iniciándose el proceso de participación ciudadana que llevará a la aprobación definitiva del mismo. 
Actas del Seminario Internacional Destinos Turísticos Inteligentes:

nuevos horizontes en la investigación y gestión del turismo

Universidad de Alicante, 26 y 27 de octubre de 2017

Tabla 6: Acciones contempladas en el Plan Director de DTI de Calp

\begin{tabular}{|c|c|}
\hline \multicolumn{2}{|r|}{ Líneas de acción estratégicas } \\
\hline Innovación & $\begin{array}{l}\text { AE1 Grupos de trabajo con empresas del sector turismo } \\
\text { AE2 Participación en iniciativas y proyectos tractores } \\
\text { AE3 Fomento de la calidad turística } \\
\text { AE4 Refuerzo de la identidad de marca Turismo de Calp } \\
\text { AE5 Creación de la Oficina Turística del siglo XXI } \\
\text { AE6 Adaptación a la Norma UNE } 178501\end{array}$ \\
\hline Accesibilidad & $\begin{array}{l}\text { AE7 Proyectos de mejora de la accesibilidad física } \\
\text { AE8 Proyectos de mejora de la accesibilidad digital } \\
\text { AE9 Formación a empresas, ciudadanos y visitantes de Calp } \\
\text { AE10 Datos turísticos en abierto }\end{array}$ \\
\hline $\begin{array}{l}\text { Sostenibilidad y } \\
\text { gobernanza }\end{array}$ & $\begin{array}{l}\text { AE11 Seguimiento y revisión de la estrategia turística de Calp } \\
\text { AE12 Generación de cartas de servicios municipales } \\
\text { AE13 Realización de campañas y acciones de participación } \\
\text { ciudadana. } \\
\text { AE14 Establecimiento y seguimiento de un sistema de } \\
\text { indicadores }\end{array}$ \\
\hline \multicolumn{2}{|r|}{ Líneas de actuación tecnológicas } \\
\hline $\begin{array}{l}\text { Información y } \\
\text { marketing }\end{array}$ & $\begin{array}{l}\text { AT1 Definición del Centro de Turismo Inteligente de Calp } \\
\text { AT2 Mejora de la Plataforma de Difusión Turística de Calp } \\
\text { AT3 Aplicación móvil oficial de Turismo de Calp } \\
\text { AT4 Central de reservas turísticas } \\
\text { AT5 Sistemas de cartelería digital. }\end{array}$ \\
\hline $\begin{array}{l}\text { Conectividad, } \\
\text { sensorización y } \\
\text { captación de datos }\end{array}$ & $\begin{array}{l}\text { AT6 Panel de control turístico } \\
\text { AT7 Señalización inteligente-balizas turísticas } \\
\text { AT8 Herramientas de captación de datos } \\
\text { AT9 Wifi público } \\
\text { AT10 Big data turístico }\end{array}$ \\
\hline
\end{tabular}

Fuente: Ayuntamiento de Calp (2017)

la sensorización, deberá permitir medir en Calp aquellos indicadores de sostenibilidad para los que hoy por hoy no existen mediciones continuas, como es el caso de la contaminación acústica o del aire. Además, el panel de control turístico deberá superar el marco estrecho de un simple cuadro de mando sobre la situación de la demanda turística en el destino y la medición de la efectividad y el alcance comercial de las iniciativas promocionales del departamento de turismo, y deberá permitir la monitorización íntegra de los diversos aspectos que afecten a la sostenibilidad del destino, recogidos bien a través de los sensores, bien a través de otras fuentes. En definitiva, 
Actas del Seminario Internacional Destinos Turísticos Inteligentes:

nuevos horizontes en la investigación y gestión del turismo

Universidad de Alicante, 26 y 27 de octubre de 2017

la inteligencia aplicada a la gestión debería permitir el ambicioso objetivo de establecer el impacto global -y no sólo económico- del modelo de desarrollo turístico elegido por el municipio y su evolución a lo largo de los años.

Desde luego, a tales efectos y como es preceptivo en el marco de las estrategias EDUSI, el Plan Director de DTI será un plan participado y consensuado con todos los agentes implicados, así como puesto a disposición de todos los ciudadanos en las webs y plataformas municipales de participación, superando las carencias detectadas en este campo en el análisis de indicadores para otros documentos de planificación municipales. Pues de no efectuarse de este modo, se corre el riesgo de que el Plan Director de Destino Turístico Inteligente se convierta en un documento aséptico, que promueva la inversión en algún elemento dedicado a facilitar la información y la vida de los turistas y con alguna incidencia en la mejora de su experiencia en Calp, no olvidando que la demanda actual ya otorga, por lo demás, una valoración ya de por sí muy elevada al destino. Pero todo ello, sin una verdadera incidencia en la sostenibilidad de Calp como destino turístico. En este caso, se perdería una oportunidad de oro, tal vez la última, para alcanzar una verdadera sostenibilidad para Calp y no un aterrizaje traumático como la última crisis económica ha desvelado durante los últimos años.

\section{Conclusiones}

En este artículo se defiende que la aplicación del concepto de DTI supone la primera oportunidad real de hacer operativa lo que hasta este momento no ha sido más que un mero desiderátum: la sostenibilidad de los destinos turísticos. La última crisis económica ha propiciado un experimento quasi-natural para valorar el escenario al que por agotamiento de su recurso básico están abocados a enfrentarse la gran mayoría de los destinos turísticos residenciales de nuestro país. En el caso de Calp, con un término municipal de reducidas dimensiones y un elevado grado de desarrollo, este límite físico-económico se encuentra cerca. Así, la crisis arroja lecciones que obligan a reconsiderar el modelo de desarrollo y la necesidad de adoptar las medidas necesarias para que en un futuro pueda reconducirse la realidad hacia dicho escenario de sostenibilidad deseable.

En el caso de Calp se pone de manifiesto que la insostenibilidad del destino no repercute, hoy por hoy, en una valoración negativa por parte de los turistas que acuden al destino. Sin embargo, es más que probable que a medida que nuevos segmentos de la demanda con mayor conciencia 
Actas del Seminario Internacional Destinos Turísticos Inteligentes:

nuevos horizontes en la investigación y gestión del turismo

Universidad de Alicante, 26 y 27 de octubre de 2017

ambiental vayan incorporándose al mercado turístico, la falta de sostenibilidad del destino se convierta en una amenaza para su continuidad y éxito. Conscientes de esta situación, en Calp, se ha abogado por utilizar un camino indirecto hacia la sostenibilidad: la sostenibilidad a través de la inteligencia. Aún en un estado primigenio, los primeros pasos han puesto de manifiesto que la tecnología, aplicada correctamente puede contribuir a mejorar la sostenibilidad del destino turístico y contribuye a mejorar la experiencia de los turistas. Sin embargo, la experiencia calpina apunta a que dichos pasos deben darse de forma paulatina, focalizando las acciones donde son realmente más necesarias y valoradas por los turistas.

La inteligencia turística debe entenderse a la escala y situación de partida de cada destino. No tiene sentido aplicar tecnología per sé, sino es para realmente mejorar la gestión y la experiencia de los turistas y la gestión de los procesos esenciales que afectan al destino. $Y$ no tiene sentido embarcarse en grandes acciones de inteligencia, cuando algunos destinos aún presentan carencias básicas que se entienden inherentes al propio concepto de destino. Pero del mismo modo, no tiene sentido embarcarse en implantar tecnologías que únicamente se destinen a mejorar la información y la gestión de las campañas de promoción dirigidas a los mismos. Se requiere, por el contrario, un enfoque amplio, que contemple a la sostenibilidad en todas las acciones a emprender, y que permita analizar la evolución del destino en este campo y la efectividad de las acciones correctoras que se implementen en este sentido.

El caso de Calp arroja lecciones importantes en este contexto y podría ayudar a otros destinos a la puesta en marcha planes de promoción de la inteligencia turística que realmente contribuyan a la sostenibilidad de la actividad turística. Por lo demás, de no aplicar correctamente -es decir, respetando la necesaria flexibilidad y dinamismo de cada uno de los destinos objeto de tratamiento- los principios de la inteligencia, el concepto de destino turístico inteligente corre el riesgo de quedar desvirtuado y, como en el caso de la sostenibilidad, quedar relegado a un uso retórico o, en el mejor de los casos, como un elemento de marketing con el que diferenciar destinos turísticos que en esencia, son lo mismo. Se perdería así una oportunidad de oro para conseguir a través la inteligencia, quizá por primera vez, la ansiada sostenibilidad de los destinos turísticos. 
Actas del Seminario Internacional Destinos Turísticos Inteligentes:

nuevos horizontes en la investigación y gestión del turismo

Universidad de Alicante, 26 y 27 de octubre de 2017

\section{References}

Agencia Valenciana de Turismo (2015). Destinos Turísticos Inteligentes. Manual Operativo para la configuración de Destinos Turísticos Inteligentes.

Ayuntamiento de Calp (2016). Estudio de la demanda y oferta turística de Calp. Ayuntamiento de Calp.

Boes, K., Buhalis, D., \& Inversini, A. (2016). Smart tourism destinations: ecosystems for tourism destination competitiveness. International Journal of Tourism Cities, 2(2). http://doi.org/10.1108/IJTC-12-2015-0032

Buhalis, D., \& Amaranggana, A. (2015). Smart Tourism Destinations Enhancing Tourism Experience Through Personalisation of Services. In I. Tussyadiah \& A. Inversini (Eds.), Information and Communication Technologies in Tourism 2015 (pp. 377-389). Cham (Switzerland): Springer.

Butler, R. (1980). The concepts of a tourist area cycle of evolution: Implications for management of resources. Canadian Geographer, 24(1):5-12.

Brundtland (1987) Our Common Future: Brundtland Report. UN. New York.

Del Chiappa, G., \& Baggio, R. (2015). Knowledge transfer in a tourism destination: the effects of a network structure. Journal of Destination Marketing \& Management, 30(10), 1757-1771. http://doi.org/10.1016/j.jdmm.2015.02.001

Gretzel, U. (2011). Intelligent systems in tourism. A Social Science Perspective. Annals of Tourism Research, 38(3), 757-779. http://doi.org/10.1016/j. annals.2011.04.014

Gretzel, U., Sigala, M., Xiang, Z., \& Koo, C. (2015). Smart tourism: foundations and developments. Electronic Markets, 25(3), 179-188. http://doi.org/10.1007/ s12525-015-0196-8

Ivars, J. A., Solsona, F. J., \& Giner, D. (2016). Gestión turística y tecnologías de la información y la comunicación (TIC): El nuevo enfoque de los destinos inteligentes. Documents d'Anàlisi Geogràfica, 62(2), 327-346. http://doi.org/10.5565/rev/ dag. 285

Kay, J. (2011). Obliquity. Why Our Goals are Best Achieved Indirectly. Profile Books. London.

Olivera Begazo M.A. (2001) Turismo Sostenible y las Agendas 21. Congreso Virtual de Turismo 2001 en la Ciudad Virtual de Antropología y Arqueología

Organización Mundial de Turismo (1993) Tourism the year 2000 and beyond qualitative aspects. OMT Madrid.

Organización Mundial de Turismo (2013) Sustainable Tourism for Development Guidebook. Enhancing capacities for Sustainable Tourism for development in developing countries. OMT Madrid.

Perles, J. (2004). Turismo, ventaja competitiva y desarrollo local. Tesis Doctoral, Universidad de Alicante. Biblioteca Virtual Miguel de Cervantes. 
Actas del Seminario Internacional Destinos Turísticos Inteligentes:

nuevos horizontes en la investigación y gestión del turismo

Universidad de Alicante, 26 y 27 de octubre de 2017

Perles, J. (2009). Calpe, causas del éxito turístico residencial. Ed. Bubok.

Perles, J. Ramón, A. (2009). La sostenibilidad financiera de los destinos turísticos residenciales en la provincia de Alicante. Un análisis preliminar. Papers de Turisme, 46:23-39

Perles, J. (2010). Valorización de productos y reestructuración de destinos turísticos maduros: el papel de las agencias de desarrollo local. Gran Tour: Revista de Investigaciones Turísticas, 2: 23-40.

Perles, J., Ramón, A., Sevilla M (2011). Determinants of the competitive advantage of residential tourism destinations in Spain. Tourism Economics, 17 (2):373-403

Perles, J. (2014). Regeneración urbana, planificación estratégica y gestión del conflicto en destinos turísticos. El caso de Calpe. PASOS, Revista de Turismo y Patrimonio Cultural, 12 (1):95-105.

Perles-Ribes, J., Ramón-Rodríguez, A., Vera-Rebollo, J.F. \& Ivars-Baidal, J. (2017). The end of growth in residential tourism destinations: steady state or sustainable development? The case of Calpe. Current Issues in Tourism. http://dx.doi.org/1 $0.1080 / 13683500.2016 .1276522$.

Perles, J. \& Ramón, A. (2017). Instrumentos de cooperación público-privada en tiempos de crisis: motor de competitividad o especie amenazada?. Cuadernos de Turismo, 39:481-494.

Segittur (2015). Informe destinos turísticos inteligentes: construyendo el futuro.

Vera J.F. (coord.) (2001) Planificación y gestión del desarrollo turístico sostenible: propuestas para la creación de un sistema de indicadores. Universidad de Alicante. Instituto Universitario de Geografía Documentos de trabajo n.ㅇ 1, 2001 $p, 7$

Wall, G. (1992). Key Challenges - What do they Mean to the Industry? Panel discussion, Tourism Stream of GLOBE'92 conference, Vancouver, BC, 15-20 March.

Xiang, Z., Tussyadiah, I., \& Buhalis, D. (2015). Smart destinations: Foundations, analytics, and applications. Journal of Destination Marketing \& Management, 4, 143-144. http://doi.org/10.1016/j.jdmm.2015.07.001 